\title{
Correction to: Modeling mortality risk effects of cigarettes and smokeless tobacco: results from the national health interview survey linked mortality file data
}

\author{
Esther Salazar*, Chunfeng Ren, Brian L. Rostron and Ghideon Solomon
}

\begin{abstract}
Correction to: BMC Public Health 21, 1773 (2021)
https://doi.org/10.1186/s12889-021-11,801-w

It was highlighted that the in the original article [1] in Table 1 and Table S3, the labels for the "Poverty level" variable (Below 100\% threshold, At or above 100\% threshold) were presented in the incorrect order. That is, label "At or above 100\% threshold" should have appeared first. Also, in the Results section, the following sentence should have appeared as: "Exclusive current SLT users, along with exclusive current and former smokers, were more likely to be non-Hispanic white and have less education (less than high school or high school diploma) and higher poverty level (at or above $100 \%$ poverty threshold)." The original article has been updated.
\end{abstract}

\section{Supplementary Information}

The online version contains supplementary material available at https://doi. org/10.1186/s12889-021-12242-1.

Additional file 1: Table S3. Demographic and socioeconomic character-
istics (weighted estimates and 95\% Cls) for NHIS participants aged 35+ at

Additional file 1: Table S3. Demographic and socioeconomic character-
istics (weighted estimates and 95\% Cls) for NHIS participants aged 35+ at the time of interview. ${ }^{a}$

The original article can be found online at https://doi.org/10.1186/s12889021-11801-w.

*Correspondence: Esther.Salazar@fda.hhs.gov

Center for Tobacco Products, U.S. Food and Drug Administration, 11785

Beltsville Dr, Calverton, MD 20705, USA

Published online: 04 January 2022

\section{Reference}

1. Salazar $E$, et al. Modeling mortality risk effects of cigarettes and smokeless tobacco: results from the National Health Interview Survey Linked Mortality File Data. BMC Public Health. 2021;21:1773. https://doi.org/10.1186/ s12889-021-11801-w. regulation or exceeds the permitted use, you will need to obtain permission directly from the copyright holder. To view a copy of this licence, visit http://creativecommons.org/licenses/by/4.0/. The Creative Commons Public Domain Dedication waiver (http://creativeco mmons.org/publicdomain/zero/1.0/) applies to the data made available in this article, unless otherwise stated in a credit line to the data. 


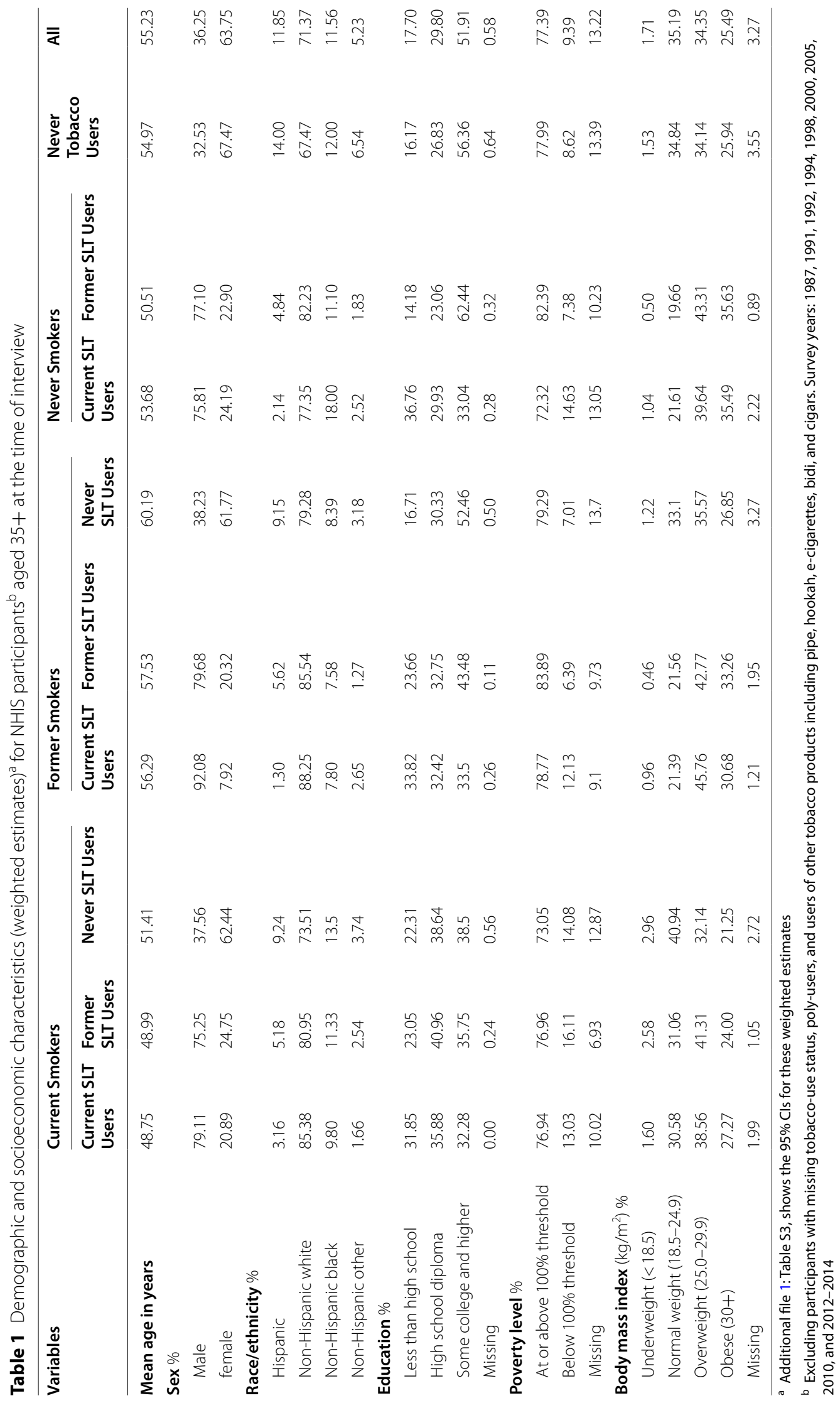

